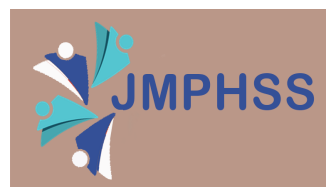

Journal of Management Practices, Humanities and Social Sciences

Vol 4 Issue 1 pp. 12-15

https://doi.org/10.33152/jmphss-4.1.3

\title{
ORIGINAL CONTRIBUTION \\ The Art of Leadership Qualities in Human Governance of Human Capital
}

\author{
Siti Sarawati Johar ${ }^{1 *}$, Linayati Lestari ${ }^{2}$, Nesreen Awada ${ }^{3}$ \\ 1, 2, 3 Tun Hussein Onn University of Malaysia, parit Raja, Malaysia
}

\begin{abstract}
The purpose of this study is to explore and discusses about the leadership qualities in human governance of human capital. This study also investigated the characteristics of leadership in human governance that have a significant impact on the human capital. This study is qualitative in nature such that a comprehensive review of existing literature was conducted. This conceptual paper discussed some of the leadership qualities needed in the formation of strong human governance of human capital. These leadership qualities include a positive dimension of values that should be interpreted explicitly and implicitly. The findings of current study highlight that the qualities of a leader are not only based on the language of his words, but also the language of his body which must conform to what is implied in his mind and soul, which is reflected in his behaviour. Moreover, the dark side of a leader will only change the landscape of the organization because there will be a pattern of reckless compliance with followers who dispel their ethics and manners. Therefore, a leader needs to put the goodness side of themselves as a highlight based on leadership to ensure that everything is in line with universal values and society demands.
\end{abstract}

Index Terms - Leadership, Qualities, Human, Governance, Capital.

Received: 19 November 2019; Accepted: 17 May 2020; Published: 28 June 2020

\section{Introduction}

Leadership is an individual's ability to influence others or subordinates towards the achievement of organizational goals. Leadership is also seen as an influence on others in performing task-related activities among organizational members. The role of leaders is crucial to ensuring that the organization they lead is successful. Leadership is essential in the pursuit of leading, controlling the behaviour of members of the organization towards the goals it has set. Leadership is also a process of generating insights, inspiring greater commitment, and being able to direct human capital efforts towards achieving organizational goals.

The integrity of an organization does not depend solely on the collaboration of all parties but is based on an aspect of employee effectiveness to act as an effective change agent and an innovative catalyst to achieve organizational objectives. Employees are a key engine of our efforts to assist, guide and move our goals towards excellence. Chronologically, employees' duties are led by the administrators of the organization, and of course they are co-chaired by the leader. Effective leadership of an institution will enable a more efficient work climate and work culture among the workforce, thus enhancing the employee's willingness to help improve organizational performance. Notably, an organization is a 'living' entity because all its members have different values and entities, whether in terms of background, emotion, desire, hope, and ambition, but they can be unified in the same direction (Johar, 2017).

However, the phenomenon that challenges many situations involving attitudes, thoughts and feelings certainly exists in any organization. Such a situation can be difficult to control and supervise if a leader is not prepared enough for all aspects of leadership and organization skills. The most important human resource in the organization is the employees who are subordinates who need to be trained to do their job well. It is the leader's responsibility to determine the direction of his subordinate to achieve the organization's goals in general and the direction of his career prospects.

Background of the study

Leaders and leadership issues have been reviewed and researched by previous researchers and this issue is increasingly interesting to address when focused on the role of a leader who is clearly involved in an organization. Although the issue is complex, the fact is that from the history, the context of leaders and leadership in any organization is closely linked to the rise of an organization. Undeniably, a leader's leadership is often a focus and an appraisal among the employees and the community to the extent that any activity is associated with staff development and the ability to fulfil the aspirations of the head of the organization (Agbozo, 2017; Putri, 2015).

The question is, to what extent does the fact that an organization's success factors depend on the leadership ability of the organization? This, in turn, brings us to another connotation that is the leadership style of a leader really dominating the level of employee motivation. Or maybe the employee's motivation level is due to other variables being variable?

\footnotetext{
*Email: ssarrajoe@gmail.com
} 
The situation that often associates the integrity and excellence of the organization with the quality of its leadership is because the element of leadership is a very important catalyst for an organization. The success and failure of an organization policy underlined has a significant connection with the credibility of the leader as the leader in the organization to motivate employees, mobilize, execute and achieve the goals they have set (Johar, 2017).

This is in line with Holzman (1992) view that leadership in an organization depends on its leader. Leaders are key to the success of an organization (Andrews \& Morefield, 1991; Bo Shing \& Xiaodie, 2017). For Sweeney (1982), however, leaders play a crucial role in determining the fall or rise and effectiveness of an organization. Of course, quality leadership leads to accepting depending on the style of leadership applied.

An authoritative leadership style clearly demonstrates the advantages of having extensive knowledge in organizational and management aspects, the role and commitment of a leader in an organization that serves as the backbone for excellence is absolutely essential. The three key elements underlying the definition of leadership are leaders, leaders, and processes that guide activities toward the achievement of goals. However, Ramaiah (1999) explained that the attempt to further define the leadership refers to specific actions taken by leaders in discharging their responsibilities such as directing tasks to subordinates. The role and function of a leader is to determine efforts to improve the effectiveness of the work process with the capacity to innovate.

In the early phases, the effectiveness of leadership in an organization is reflected in leadership traits such as high self-esteem, wisdom, honesty, the ability to influence subordinates and so on (Robbins, 2005). These traits will be more evident when looking at behaviours practiced by leaders such as autocratic, democratic, laissez faire, task-oriented, humanoriented and so on. By assessing this behaviour trait or leadership style, it is not possible to be appropriate only in certain situations such as where work demands are completed soon and involves immediate customer demand, so a task-oriented leadership style is essential for a leader (Kosasih, 2018). However, in situations where teams work together and require the involvement of all parties in decision making, there is a need for democratic or human-oriented leadership.

Leadership theory has been expressed as a marker of a leader's leadership style in the process of improving performance and often a successful or unsuccessful leader will be distinguished according to their leadership style. All these approaches to leadership theory serve as a means of identifying leaders' behaviours during leadership.

\section{Purpose of the study}

The purpose of this study is to explore and discusses about the leadership qualities in human governance of human capital. This study was investigating as well about the characteristics of leadership in human governance which that have a significant impact on the human capital and the way we discuss it is by the characteristics in the human development.

\section{Characteristics of Leadership in Human Development}

From the aspect of charismatic leadership, we should be the best example for us down the biological along with acknowledging the greatness of the Prophet Muhammad as the leader of a very dear Muslims and glorified God. In fact, every action, view and teaching of the Messenger of Allah is always based on the revelation of Allah Almighty. Michael Hart in his book entitled 'One Hundred Influential Persons in History' says that the Prophet Muhammad was not only a leader of the world, but also a world leader (Hart, 1978).

Many facts have shown that as the driving force of the Arab conquest
(Muslims), his political leadership influence was always in the forefront. Michael Hart considers the existence of a very balanced combination of worldly and hereafter needs until he recognizes that the Prophet Muhammad was a man of great influence in human history throughout the ages (Holzman, 1992). While at any level of leadership of the Muslims, the ability to lead by the Prophet's Messenger should be the best example and ideal idol for Muslims. Indeed, all human beings are caliphs on this earth. This is a clear guideline for workplace leaders to be relevant examples for employees. The characteristics of leadership that need to be taken by individuals who are leaders are discussed in further discussion.

\section{Beloved Leaders}

We may be able to love others without leading them, but we may not be able to lead others without loving them. Therefore, it is imperative for us to be good human beings especially if we are at the helm of a leader. The unloved leader gives a sign of the difficulty for the employee to grasp and accept the aspirations of his boss with a heartbeat. The personality of a leader greatly influences the emotional and mental factors of the workforce (Johar, 2013).

Is it too difficult for us to make the Prophet's character and personality a great example to help us navigate our way of life more dynamically? We should consider the extent to which the Prophet (PBUH) acted, thought and interpreted the situation as an example of speaking to others, he would have given due care and would have his whole body in front of him. Occasionally he would sneer a joke and it would show how high he felt in his arms to be with others that he could accept others as he was. He is also very much loved by people from all walks of life. This is in line with the word of Allah Almighty: "Then include believers who admonish one another, to be patient and to love one another" (Surah Al- Balad, verse 90: 7).

Good personalities and character are a priority that will allow a leader to be a model or an idol that employees can emulate. A leader is to be respected rather than feared, to be loved rather than scorned, admired rather than feared and honoured rather than humiliated (Agustian, 2008). Every vision and mission of the organization can be achieved voluntarily when employees can work more faithfully.

\section{Trusted Leaders}

According to Agustian (2008) through the Emotional Spiritual Quotient leadership model, a person with high integrity values is a courageous individual who strives to achieve everything that is aspired to base on pure values (Agustian, 2008). Such individuals will also be more consistent in making choices for their choices in life. As a leader in any job organization, a principled attitude and integrity will make the employee emulate the boss. Workers' trust in their leader builds confidence and expectations and aspirations are the same.

A trusted leader is also viewed from the standpoint of justice and honesty (Agustian, 2008). This is in line with the best example we can take from the character and personality of the Messenger of Allah. His just and equitable attitude can be seen in the events of a civil war involving two large groups who disagree about who really needs the honour to put the Hajarul Aswad stone in its place.

The Messenger's wise decision to help resolve the issue fairly and honestly satisfied all involved. This can show how the dissenting parties had such strong faith in the Prophet's ability, that they were confident of seeking his help in resolving the dispute. Finally, the solution of the Messenger of Allah was resolved to resolve the conflict. For example, leaders need to be trusted in order to build confidence in their followers for reference in the face of any problems. Successful leaders create the confidence of their followers to enable the task to be carried out more effectively and 
systematically (Johar, 2017).

\section{Leaders as Guides}

The next step as a leader that requires high leadership is the ability to become a mentor. Leader are not judged on the broad aspects of their power, but they do need to be evaluated on their ability to act as a motivator that can stimulate a person's psychological well-being. At this stage the leader can develop a strong trust among the follower towards the leader (Johar, 2013). That confidence is further strengthened by the element of loyalty that is shared by the positive motivation and self-concept of the employees towards the chairman and co-followers. It shows how closely the elements of a leader's needs have such simple qualities as a clean heart, mature mind, willingness, perseverance and patience in dealing with any situation in the organization.

There are seven elements that often haunt the human soul and mind that cause various problems in human relationships, even human relations with Allah Almighty. These elements are the shackles of negative prejudice, the shackles of the principle of life, the shackles of experience, the shackles of self-interest, the shackles of point of view, the shackles of compulsion and the shackles of fanaticism (Agustian, 2008).

These shackles are one of the reasons why the family's accounts in the human soul are so volatile that they end up destroying the soul and consuming themselves. With a deep appreciation of the need to strengthen emotional intelligence and spiritual intelligence from a religious perspective, the human soul and emotions should be refined to form a positive schematic. The effect can lead to a more peaceful human life when every human being can live with such virtues as breastfeeding, tolerance, kindness and goodwill and gratitude. The relevance of this situation to a leader is that a full-hearted and thoughtful leader will not be bound by negative elements that can prevent him from being a mentor.

Revealing the paradox of how a leader can influence followers is evident whether they are viewed positively or negatively. For example, we see how Karl Marx, a leader of the communist flow in contradiction to the flow of capitalism, was found to be capable of diverting the human mind and soul into the flow of human life. The influence of this communist ideology spread not only in Russia, but also in China and Southeast Asia. In Malaya itself in the 12 years from 1948 until 1960, the state of emergency has been declared by the government (Ling, 2004). An emergency had to be declared for the need to protect the people and the country in the face of communist violence and destruction. Their mode of operation was to influence the thinking of the working class, including through the unions to mobilize the rebellion and create chaos to bring down the country's administration.

Many lives were lost, and many public and private property was destroyed. The chaos is going on here and there until the people are in pain and there is no freedom. After the communist party was overthrown, the country came back to full strength to repair the damage that had cost millions (Ling, 2004). Is it worth it for the communists to blind their eyes to the concept of struggle that is against the norm? In a variety of scenarios and circumstances that have gripped the political journey and the spirit of nationalism, there have been many people of the world at that time who could not stand the reality of the ground of truth, especially when influenced by leadership knowledge and the context of the struggle for false ideologies and violations of human norms.

In the issue, it is possible to see how the communist leader acts as a mentor to his members and even as a motivator in his flow. The meanings of the struggle given by the communist leaders at that time could realize their objectives and as if there were no 'illegal' terms in any of their modes of operation. But it turns out that it has sacrificed too much of its moral value and robbed the people's right to a happy life. Their followers were indeed guided, but it turned out that they were guided in the darkest path. Even in the dark, their aspirations and dreams are lost along with the disappearance of their leaders in the jungle.

When we speak on the negative side, the communist struggle of the day remains clearly on the wrong path and violates the human nature that truly wants the truth to live based on religion and pure values. No human on earth wants to live in ruin and violence. However, changes in the thinking and stigma of thinking are also due to lack of knowledge and exposure to the consequences and consequences of actions. The situation becomes more chronic when individuals who are members of the group believe their leader is very competent. They can uphold their aspirations and following what the leader brings and delivers. From a very shallow perspective, the struggle is seen as the best struggle to overcome what is worst thought (Johar, 2013).

Whether imperialist power of Japan in Malaya with the slogan 'Asia for the Asians', nor imperialist western powers, namely the British in Malaya, each with their own agendas to allow their followers deeply affected by every schemata are nurtured in the minds and souls to embrace with the vision and mission of the organization. On the contrary, does it lead to a path that is in line with the truth sought by religion and does it lead to the value of the leader's leadership in leading a pure struggle for universal harmony? In fact, they are willing to sacrifice their universal value only to uphold the false values of their creation in a world riddled with various elements such as prejudice and discrimination. Their leadership is from the negative side, leading to a negative wave in the lives of the victims. The impact left behind is fraught with harm to the development of the nation and society (Johar, 2013).

Tracing the history of colonization, nor western powers in Malaya before independence. British leadership put the dominant force them to design the patterns and trends as well as the economic administration in Malaya by reference. Instead, they create new scenarios in social, cultural and educational phenomena according to their imperialism dimension through a policy of rupture and order. As a result, the people of Malaya through a system of economic, social and educational separated by ethnicity. Soldiers and followers in the British administration unite, mind and energy realize what their leadership has commanded. From the positive side effect of conformity to the head, British colonial troops managed to build a new climate in world Malaya. However, from the negative side they have left a profound impression on Malaysia now. The impact goes beyond the context of unity that has been a part of the government's past and in its quest to unite all ethnic groups. The struggle is a process and is still ongoing today for the sake of national security (Johar, 2017).

Return to the reality of human nature and life. Again, we must recognize that a leader needs to guide, direct, influence and empower his followers emotionally and mentally with the right direction in the right path. This commitment is not an easy task as it will be at risk from the perceptions and behaviours of each follower. But a leader's success in guiding his followers is of great value as the followers will inherit the leadership style. That kind of guidance is sure to be a success from generation to generation.

\section{Leaders Personality}

The leader of any organization should have a unique one-on-one personality with functions that must be respected, loved, trusted and capable of consistently guiding its followers. The articulation element allows the emotional and spiritual intelligence of leader would look more presentable as a capable leader to lead his organization in the direction of the demands of work into worship only Allah SWT. A virtuous leader must be wise in placing himself in various situations and refraining from any harm that may result in the defamation of others.

From the communication aspects to the behavioural aspects, every- 
thing needs to be considered in order to bring a positive culture into the day-to-day climate of organizations that have a diverse impact. We cannot deny that the time frame of a leader and employee at work is longer than the time at home. Therefore, we also need to understand how the work environment also affects the attitude and thinking of the employee. The relevance of this point is the need for a leader to be able to emerge as a leader who is dignified and has social skills and a high level of awareness of the workforce so that employees feel more secure and secure (Shah, 2004).

The success of a leader with a noble personality we can highlight from various past histories. An example of the Muslims' success in capturing the city of Constantinople through the struggle of their leader, Sultan Muhammad A l-Fateh. From an early age, he was educated in religious studies and trained in modest living (Talib, 2008). He was also strengthened by the science of heroism and war. From an early age, he was keen in thinking and devising the strategy of operating a government centre. He was ambitious as well to conquer the city of Constantinople, though he realized it was not an easy struggle. However, the words of the Prophet Muhammad, revealed to him 800 years earlier, were deeply embedded in the heart and mind of Sultan Muhammad A l-Fateh and thus became a constant motivation in his pursuit of victory (Talib, 2008). The word of Prophet Muhammad (PBUH) means: "The city of Constantinople will fall into the hands of Islam. The leader who conquers is the best of the leaders and the forces under his command are the best of the troops" (Ahmad bin Hanbal Al-Musnad's History Hadith 4/335).

Sultan Muhammad A l-Fateh willing to participate in building a wall along followers and his army, even had demolished it by an army of Constantinople. He was greatly loved and admired by the people, and even his followers and the people were willing to fight together to conquer Constantinople. Sultan Muhammad al-Fateh was also a good king who always talked in worship and conduct with fellow human beings. His personal strength made him worthy of being recognized as a great leader. Finally, in 1453, the city of Constantinople fell into the hands of Muslims led by Sultan Muhammad al-Fateh and the name of the city was changed to Islambol. Now more commonly known as Istanbul is one of Turkey's most famous regions. Sultan Muhammad Al-Fateh's life ended when he died for being poisoned by a Jew at the age of 49 (Talib, 2008). But his name still thrives in the history of Islam as a leader who is bold, pious and fearful. This is one of the examples of leaders who are virtuous individuals who can lead their followers on the right path to achieving Islamic martyrdom.

\section{Limitations and Future Research Directions}

This study explored and discussed the leadership qualities in human governance of human capital. A number of qualities have been identified that are vital for human governance yet, there are many characteristics and qualities of leaders that have not been discussed in this study. In future, researchers are encouraged to enhance this work and explore other leader dynamics that are crucial for human capital governance. Specifically, how do destructive leaders hamper the growth and development of human capital is an area worth exploration.

\section{Conclusion}

Waves and currents that enhance the emotional and spiritual of human capital within the organization can also help enhance the element of employee behaviour in a more dignified and committed manner to improve the quality of work. Aspects of leadership also need to be understood as a dimension of the guiding framework to be the best example of how an organization operates in the human governance. Strength through the domain of psychology including emotional, mental and physical aspects can help create a more principled, superior personality in terms of communication, knowledge, soul and mind. With such positive force, people can emerge as citizens of a nation that is admired and respected throughout the world. The country is capable of being stable with strong defences, more spirited and first-class mentality people.

\section{References}

Agbozo, G. K. (2017). The effect of work environment on job satisfaction: Evidence from the banking sector in Ghana. Journal of Human Resource Management, 5(1), 12. doi:https://doi.org/10.11648/j.jhrm.20170501.12

Agustian, A. G. (2008). Emotional Spiritual Quotient ESQ: Rahsia successfully built emotional and spiritual intelligence. Jakarta, Indonesia: Arga Publishing.

Andrews, R. L., \& Morefield, J. (1991). Effective leadership for effective urban schools. Education and Urban Society, 23(3), 270-278.

Bo Shing, L. A., \& Xiaodie, P. J. (2017). Exploring the relationship between leadership, organizational culture, trust, and effectiveness of knowledge sharing by forced learning. Journal of Administrative and Business Studies, 3(2), 89-104. doi:https://doi.org/10.20474/jabs-3.2.4

Hart, M. (1978). The 100: A ranking of the most influential persons in history. New York, NY: Citadel Press.

Holzman, M. (1992). Do we really need" leadership"?. Educational leadership, 49(5), 36-40.

Johar, S. S. (2013). Dimension of neuroticism personality among leader and the impact towards self-esteem of employee at the workplace. ProcediaSocial and Behavioral Sciences, 91, 588-593.

Johar, S. S. (2017). Exploration of psychology in organizations: Positive or negative sides? Parit Raja, Malaysia: UTHM e-bookstore.

Kosasih, A. (2018). The influence of transformational leadership, organizational culture and employee work motivation on employee job satisfaction and its implications for PDAM employee performance in Banten province. Journal of Government and Civil Society, 1(2), 159-190.

Ling, H. H. (2004). The emergency, 1948-1960: The social condition in Malaya. Kuala Lumpur, Malaysia: University of Malaya Press.

Putri, Y. R. (2015). Transformational leadership and its impact to lecturers intellectual capital factors in Telkom economics and business school Telkom University. International Journal of Business and Administrative Studies, 1(1), 35-41. doi:https://doi.org/10.20469/ijbas.10006

Ramaiah, A. L. (1999). Educational leadership: Present challenges. Selangor, Malaysia: IBS Books.

Robbins, S. P. (2005). Organizational behavior. Englewood Cliffs, NJ: Pearson Prentice-Hall.

Shah, I. M. (2004). Introduction to industrial psychology \& organization. Johor Bahru, Malaysia: UTM Publisher.

Sweeney, J. (1982). Research synthesis on effective school leadership. $E d-$ ucational Leadership, 39(5), 346-52.

Talib, A. L. (2008). Sultan muhammad al-fateh: Conqueror of constantinople. Kuala Lumpur, Malaysia: PTS Litera Utama. 